\title{
Body Fat Percentage and Body Mass Index for Students and Staff of the College of Nursing/ Hawler Medical University
}

Ibrahim Hasan Mustafa ; Department of Nursing, College of Nursing, Hawler Medical University, Erbil, Iraq. (Correspondence: ibrahimzmar@yahoo.com )

\section{ABSTRACT}

Background and objectives: The finding of an association between health and body composition mandated the necessity for frequent testing of body composition for all. These studies aimed to analyses body fat percentage and body mass index and identify the relationship between results of both tests for nursing students and staff working in the College of Nursing, Hawler Medical University.

Methods: In this study two samples were recruited: 158 students (111 females and 47 males) and 112 staff (51 females and 61 males). Body weight was measured and body mass index was determined. Body fat percentage was measured by Omron HBF 306 CN. The data were analyzed by Social Package for Social Sciences version 22, T-test and correlation coefficients were used ( $p$ value $\leq 0.05$ was considered significant).

Results: Mean body mass index of students in both genders were within normal range (23.4 for male and 22.9for female), while that of the staff in both genders was in the overweight range (27.2 for male and 28.4 for female). The mean body fat percentage in students was normal in both genders, while that of the staff was high. There is proportion of low body fat percentage and absence of very high body fat percentage in students against considered proportion of very high body fat percentages in staff; also the levels of body mass index were inconsistent with the levels of body fat percentage in both samples. There was statistically significant moderate positive correlation between body mass index and body fat percentage in both samples.

Conclusion: Body mass index could not indicate the same body fat percentage.

Keywords: Body mass index, Adipose tissue, Association, Iraq

Received: $11 / 3 / 2018$

Accepted: 9/9/2018

Published: 30/11/2018

\section{INTRODUCTION}

Health status depends much on body composition status therefore its frequent measurement is necessary for the health and fitness of all including general population, athletes, and children [1]. Studies have found that there is direct correlation between body composition and health continuum in all levels ranging from mortality and morbidity, to immunity status, longevity, and athletic performance for both genders and for all ages. Body composition is the ratio of fat and fat free mass (FFM). In human body fat percentage can be determined by dividing fat mass per kilo gram (kg) or deciliter (dl) by the whole body mass weight per $\mathrm{kg}$ or $\mathrm{dl}$ [2-4]. Body Mass Index (BMI) is simple method for defining body weight and obesity and it's widely used for all age categories and for both genders [5]. BMI is calculated by dividing weight in kilogram by height in meter square (the unit is $\left.\mathrm{kg} / \mathrm{m}^{2}\right)[6,7]$. Although the BMI method has some benefits because it's easy, safe, inexpensive, and able to gather data from a large number of respondents through screening, BMI measurements can be considered scientifically deficient because the method cannot measure fat percentage, which is the opposite of other methods including bioelectrical impedance 
analysis (BIA)[8-10]. There are several methods for measuring body fat percentage like Skin Fold method, Anthropometric measurement, Dual Energy X-ray, Bioelectrical Impedance Analysis (BIA), among others [11]. BIA is widely used by researchers and clinicians to estimate fat percentage for all age categories [5]. BIA depends on special scale or device. The process measures body resistance for electrical current through sending small un harmful amount of electrical current $(50 \mathrm{~Hz})$ through the body either from hand to hand or leg to leg, depending on the type of device $[1,12]$. BIA device can measure body resistance for electrical current which help to estimate body water, fat free mass, and body fat ratio [13]. The method has several advantages because it is easy, fast, painless, safe, inexpensive, requires minimal skill scan be used for healthy individuals and for some chronic conditions such as mild to moderate obesity, diabetes mellitus, and for other health problems which have not water distribution problems in body $[12,14]$. The BIA method is used to identify body composition not for identifying therapy or treatment regimens [12]. The process depends on entering data related to body resistance, reactance, age, height, weight, and sex of participant's in the reputation (or device) [15]. There are many types of BIA devices: hand to hand, finger to finger, knee to knee, and foot to foot and others $[16,17]$. According to the author's knowledge, there have been no previous studies conducted in Erbil to analyze body fat percentage. As a result, this study aimed to analyze body fat percentage and body mass index, and identifying relationships between the results of both measurements for students and staff of the College of Nursing, Hawler Medical

\section{METHODS}

University.

A cross-sectional study was conducted at the College of Nursing, Hawler Medical University, Erbil/ Iraq from February 4 to May 4, 2017.

In this study, the convenient sampling method was used to recruited 158 students (111 females and 47 males) and 112 staff (51 females and 61 males). Students aged $\geq 20$ years, from second, third and fourth years in Nursing College, and from both departments, Nursing and Midwifery. All staff who worked during study period and gave consent for participating in study were included. Those who had pacemaker or were using hydrocortisone drugs and pregnant women were excluded. The ages of participants were categorized in accordance with the recommended body fat percentage guidelines of the National Institutes of Health /World Health Organization (NIH/WHO). Which showed in

Table1: Interpreting the body fat percentage result*

\begin{tabular}{llllll}
\hline Gender & Age & Low & Normal & High & Very high \\
\hline Female & $20-39$ & $<21.0$ & $21.0-32.9$ & $33.0-38.9$ & $\geq 39.0$ \\
& $40-59$ & $<23.0$ & $23.0-33.9$ & $34.0-39.9$ & $\geq 40.0$ \\
& $60-79$ & $<24.0$ & $24.0-35.9$ & $36.0-41.9$ & $\geq 42.0$ \\
& Age & Low & Normal & High & Very high \\
Male & $20-39$ & $<8.0$ & $8.0-19.9$ & $20.0-24.9$ & $\geq 25.0$ \\
& $40-59$ & $<11.0$ & $11.0-21.9$ & $22.0-27.9$ & $\geq 28.0$ \\
& $60-79$ & $<13.0$ & $13.0-24.9$ & $25.0-29.9$ & $\geq 30.0$ \\
\hline
\end{tabular}

* According to the recommended body fat percentage guidelines of the National Institutes of Health / World health organization (NIH/WHO). 
Tools and methods of data collection where through: i) Anthropometric Measurement: weight, height and BMI. The height was taken barefoot using tape measure in centimeters; it was recorded in to nearest millimeter. The weight was measured in kilograms, without shoes and wearing clothing, by a digital weighing scale. One kg was the estimated weight of the clothing and it was subtracted from whole body weight of each participant. Checks on the scale were conducted routinely before recording the weight of each subject. The body weights were recorded when the display of body weight became stabilized. The BMI calculated was weight in kilogram /height in meter ${ }^{2}$ and was used to assess the nutritional status of subjects. A BMI score lower than 18.5 indicated low body weight, a score between 18.5 and 24.9 was considered normal, a score between 25 and 29.9 was considered overweight, and a score of 30 or more was considered obese [18]. ii) Bio-electrical impedance was used to determine body fat percentage and it was measured by Omron HBF 306CN.The adopted recommendations for body fat percentages range are shown in table 1 [18].

The study was approved by the Ethical Committee of College of Nursing, Hawler Medical University. All participants gave verbal consent after explaining the purpose of the study and anonymous were emphasized before participating in the study.

The data were analyzed by social package for social sciences (SPSS version 22). Frequency, percentage, means, t-tests, and correlation coefficients were used. A $p$

\section{RESULTS}

value $\leq 0.05$ was considered significant.

Results show that there were no statistically significant difference between samples (students and staff $p$. values were 0.40 and 0.14 respectively) (Table 2 ).

Table 2: Study samples by gender, age, and body composition

\begin{tabular}{|c|c|c|c|}
\hline \multicolumn{4}{|c|}{ Students } \\
\hline Variables & $\begin{array}{c}\text { Male } \\
(n=47) \\
\text { Mean } \pm \text { S.D }\end{array}$ & $\begin{array}{c}\text { Female } \\
(n=111) \\
\text { Mean } \pm \text { S.D }\end{array}$ & t-test \\
\hline Age & $21.4 \pm 1.4$ & $21.0 \pm 1.06$ & 0.079 \\
\hline Weight & $69.8 \pm 9.7$ & $57.8 \pm 9.8$ & 0.0001 \\
\hline Height & $173.0 \pm 5.5$ & $159.2 \pm 5.9$ & 0.001 \\
\hline BMI & $23.4 \pm 3.2$ & $22.9 \pm 3.5$ & 0.403 \\
\hline $\begin{array}{l}\text { Body fat } \\
\text { percentage }\end{array}$ & $13.57 \pm 5.7$ & $24.4 \pm 5.9$ & N/A* \\
\hline \multicolumn{4}{|c|}{ Staff } \\
\hline Variables & $\begin{array}{c}\text { Male } \\
(n=61) \\
\text { Mean } \pm \text { S.D }\end{array}$ & 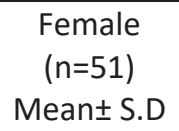 & t-test \\
\hline Age & $40.8 \pm 9.2$ & $40.04 \pm 9.9$ & 0.646 \\
\hline Weight & $82.3 \pm 11.3$ & $72.02 \pm 15.2$ & 0.001 \\
\hline Height & $173.6 \pm 6.2$ & $159.1 \pm 5.9$ & 0.001 \\
\hline BMI & $27.2 \pm 2.9$ & $28.4 \pm 5.4$ & 0.141 \\
\hline $\begin{array}{l}\text { Body fat } \\
\text { percentage }\end{array}$ & $24.9 \pm 5.0$ & $34.5 \pm 6.4$ & $\mathrm{~N} / \mathrm{A}^{*}$ \\
\hline $\begin{array}{l}\text { Age } \\
\text { categories } \\
* *\end{array}$ & Mean \pm S.D & Mean \pm S.D & \\
\hline$(20-39)$ & $22.7 \pm 5.3$ & $31.7 \pm 7.1$ & \\
\hline$(40-59)$ & $26.7 \pm 3.9$ & $37.7 \pm 3.6$ & $\mathrm{~N} / \mathrm{A}^{*}$ \\
\hline$\geq 60$ & $30.7^{* * *}$ & $46.6 * * *$ & \\
\hline
\end{tabular}

*Not applicable because body fat percentage natural is higher in women than men

**Age categories according to recommended body fat percentage for age and gender

$* * *$ Only one participant in male groups and one in female group were 60 year therefore there was no result of mean in this age group

Results show that the highest percentage (67.7) \% of students had normal BMI, followed by $20.9 \%$ of them who were overweight. Regarding BMI in staff in table 3 shows that the majority $(55.4 \%)$ of the sample were overweight, followed by $22.3 \%$ who were obese, and $21.4 \%$ were of normal weight. The table shows that more 
than half $(54.4 \%)$ of students had a high body fat percentage followed by $38.6 \%$ who were of normal weight, and $7 \%$ who had a low body fat percentage. Regarding staff, those having normal body fat percentage constituted $25.9 \%$ of the sample, compared to $38.4 \%$ who had high and $33.9 \%$ who had very high body fat percentage (Table 3).

Table 3: Study samples by body mass index and body fat percentage of nurses and team-leaders

\begin{tabular}{lcc}
\hline & $\begin{array}{c}\text { Students } \\
\text { No. (\%) }\end{array}$ & $\begin{array}{c}\text { Staff } \\
\text { No. (\%) }\end{array}$ \\
\hline BMI Levels & & \\
Under weight & $9(5.7)$ & $1(0.9)$ \\
Normal (18.5-24.9) & 107(67.7) & 24(21.4) \\
Overweight (25- & $33(20.9)$ & $62(55.4)$ \\
29.9) & & \\
Obesity (30+) & $9(5.7)$ & $25(22.3)^{*}$ \\
Body fat & Students & Staff \\
percentage levels & No. (\%) & No. (\%) \\
& & \\
Low & $11(7)$ & $2(1.8)$ \\
Normal & $61(38.6)$ & $29(25.9)$ \\
High & $86(54.4)$ & $43(38.4)$ \\
Very high & $0(0.0)$ & $38(33.9)$ \\
Total & $158(100)$ & $112(100)$ \\
& & \\
\hline
\end{tabular}

Results shows that there was positive statistically significant correlation between BMI and body fat percentage in both samples students $r=0.58, \quad$ ( $p$. value $<0.0001)$, and staff $r=0.59$, ( $P_{-}$value $\left.<0.0001\right)$ (Figure 1 and Figure 2).



Figure 1: Scatter plot between body mass index and body fat percentage for students

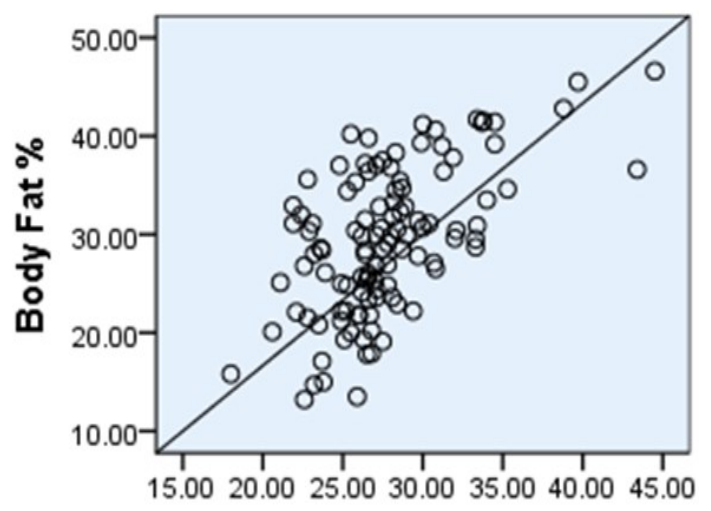

Body Mass Index

Figure 2: Scatter plot between body mass index and body fat percentage for staff

\section{DISCUSSION}

The mean BMI measurements of males and females in the student sample were normal according to WHO adult standards [19]. A study of Carpenter et al. (2013), which involved 1029 students found that the mean of $\mathrm{BMI}$ of males and females were normal $(24.4 \mathrm{~kg} / \mathrm{m} 2)(22.0 \mathrm{~kg} / \mathrm{m} 2)$ respectively and it's similar to American's BMI population [20]. Among staff, the mean $\mathrm{BMI}$ in females was higher than that 
of males, but results were not statistically significant. Both means of males and females were overweight according to WHO standards [19].A study in Nigeria, which sought to identify prevalence and overweight of staff working in University Usmanu Danfodiyo showed that the highest percentage $(50 \%)$ of sample was top normal BMI $(25 \pm 4)$ according to WHO standards[21]. A study of Kawamoto et al indicated that frequency of overweight and obesity were higher in elderly people [22].

The present study shows that the means of body fat percentage among students were normal in both genders, according to the recommended body fat percentage range for age and sex [18] Table 1. Carpenter et al. (2013) found that, in males, the mean of body fat percentage was normal among Asian and White groups, while it was high among the Hispanic group and other groups. In females, Carpenter et al. (2013) found that the mean body fat percentage was normal in all groups [20]. Our study findings are comparable. Furthermore, Weaver et al. (2009), sampled healthy adults aged 18 to 32 years old and found that the mean body fat percentage was17.2 in males and 25.4 in females [23]. Both of these measurements are normal according to the recommended body fat percentage for their age [18] Table 1. This study shows that among staff, the mean body fat percentage was high in both groups of males, while for the females, it was above normal for one group and was high in the second group, according to recommended body fat percentage [18].Pongchaiyakul et al. (2004) found that among436 participants in Thailand, the mean body fat percentage was normal in males and females [24]. The present study shows that there was inconsistency between the BMI measurement and levels body fat percentage in both groups of people (students and staff).
In students, those with normal BMI constituted the majority of the sample, while the majority of the sample had high body fat percentage. Also7\% of students had low body fat percentage, and absence of very high body fat percentage. In the staff group, the majority of people were overweight and obese according to their $\mathrm{BMI}$ measurements and they had high and very high in body fat percentage. There were differences between the proportions of levels in both tests. A study conducted at Bowen University which involved a sample of 300 students showed that the highest ratio $(73 \%)$ of $\mathrm{BMI}$ test was normal, followed by $12 \%$ was overweight. Regarding body fat percentage, the highest percentage of people (41.3\%) had normal body fat percentage, followed by $37.7 \%$ which had low body fat percentage [25]. A study carried out by Akindele et al. in Nigeria involved 1571 subjects ( $>18$ years) from different ethnic groups residing in an urban setting results, and this study showed that there was consistencies between BMI levels and body fat percentages levels[26].Result shows that there were moderate positive correlations between BMI and body fat percentage in both samples (students and staff). The study by Akindele and his colleagues mentioned that there was strong positive correlation between body fat percentage and $\mathrm{BMI}$, and age and sex are predictors of this association [26].

\section{CONCLUSIONS}

This present study demonstrated that there were no significant differences between females and males regarding BMI in both samples (students and staff). There were inconsistencies among levels of BMI and body fat percentages in both samples. There was a moderate significant positive correlation between $\mathrm{BMI}$ and body fat percentage in both samples. 


\section{CONFLICT OF INTEREST}

The author report no conflict of interests.

\section{REFERENCES}

[1] Ortansa IO., lleana GA. The importance of body composition measurement at athletes and nonathletes.Sports Medicine J. 2006; 6(2). Available from: http:// www.medicinasportiva.ro/SRoMS/ english/Journal/No.6/The\% 20importance\%20of\%20body\% 20composition\%20measurement\%20at\% 20athletes\%20and\%20non\%20athletes\% 20full.html. [Accessed: in Feb. 6, 2018].

[2] Abdelaal M., Le Roux CW., Docherty NG. Morbidity and mortality associated with obesity. Annales of Translational Medicine . 2017 Apr; 5(7): 161.

[3] Biodynamics. Clinical desk reference for Bioelectrical Impedance Analysis Testing. 2017Available from:https:// www.biodyncorp.com/pdf/ clinician_desk_reference_bio.pdf. [Accessed:in Feb. 6, 2018].

[4] Scott JR. Body composition and body fat percentage. How to measure and interpret your body fat percentage. Nov. 22, 2017. Available from: https:// www.verywellfit.com/what-is-bodycomposition-3495614.[Accessed:Feb. 6, 2018].

[5] Bhurosy T., Jeewon R. Pitfalls of using Body Mass Index in assessment of obesity risk. Current Research in Nutrition and Food Science Journal., 2013;.1(1), 71-76.

[6] Tyrrell J., Jones SE., Beaumont R., Astley CM., Lovell R., Yaghootkar $H_{\text {., }}$ et al. Height, body mass index, and socioeconomic status: mendelian randomisation study in UK Biobank. British Medical Journal. 2016; 352. Available from: doi: https:// doi.org/10.1136/bmj.i582.
[7] Kuczmarski RJ, Flegal KM. Criteria for definition of overweight in transition: background and recommendations for the United States. American Journal of Clinical Nutrition. 2000; 72(5): 10751081.

[8] Tremblay S. Body mass index advantages and disadvantages. Livestrong.com. last update Jul. 18, 2017. Available from: http:// www.livestong.com/articale/93472problems-bmi.[Accessed: Feb. 7, 2018].

[9] Han TS. Sattar N., Lean M. assessment of obesity and clinical implications British Medical Journal. Sep. 28, 2006; 333. Available from:http:// doi.org/10.1136bmi.333. 7570.695 . [Accessed: Feb. 7, 2018].

[10] Rothman KJ. Body Mass Index -related error in measurement of obesity. International Journal of Obesity. 2008; 32 (3):56-9.

[11] Guedes DP. Clinical procedures used for analysis of the body composition. Revista Brasileira de Clineantropometria e Desempenlo Human_Journal . 2013; 15 (1): 113-129.

[12] Mylott E., Kutschera E., Widenhorn R. Bioelectrical impedance analysis as a laboratory activity: At the interface of physics and the body. American Journal of Physics. 2014; 82 (5): 520-29.

[13] Rani GS. Different measuring techniques for body fat analysis. International Research Journal of Science and Engineering, 2015; 3(3): 98106.

[14] Roubenoff R. Applications of bioelectrical impedance analysis for body composition to epidemiologic studies. American Journal of Clinical Nutrition. 1996; 64(3suppl):459-62.

[15] US National Library of Medicine. Bioelectrical impedance analysis in body composition measurement: national institutes of health technology assessment conferences statement. American Journal of Clinical Nutrition. 1996; 64 (3 supply): 524-532. 
[16] Peterson JT., Repovich ES., Parascand CR. Smartphone-based Bioelectrical Impedance Analysis Devices for obesity management. British Medical Journal. 2015; 333(7570):695-8.

[17] National Institution of Health technology assessment conferences statement. Bioelectrical Impedance Analysis in body composition measurement. Nutrition Journal. December 12-14, 1994.

[18] Gallagher D., Heymsfield SB., Heo M. Healthy percentage body fat ranges: an approach for developing guidelines based on body mass index. American Journal of Clinical Nutrition. 2000; 72(3): 694-701.

[19] James PT, Leach R, Kalamara E, Shayeghi $\mathrm{M}$ : The worldwide obesity epidemic. Obesity Research Journal. 2001; 9 (4):S2228-S0033.

[20] Carpenter CL., Yan E., Chen S., Hong K., Arechiga A., Kim W., et al. Body fat and body mass index among multiethnic sample of college-age men and women. Journal of Obesity. 2013. Available from: file:///C:/Users/KAWA\%20IT/Downloads/ JOBES2013-7906541\%20(1).pdf.

[Accessed in February, 21, 2018]

[21] Nkwoka I.J., Egua M.O., Abdullahi M., Sabi'u A., Mohammed A.I. (2014).Overweight and obesity among staff of UsmanuDanfodiyo University, Sokoto, Nigeria. International Research Journals. 2014; 5(8): 290-295.

[22] Kawamoto, R., Ohtsuka, N., Ninomiya, D. and Naka-mura, S. (2008) Association of obesity and visceral fat distribution with intima-media thickness of carotid arteries in middle-aged and older persons. Internal Medicine Journal. 2008; 47(3): 143-9. doi:10.2169/ internalmedicine.47.0478.

[23] Weaver A M., Hill AC., Andreacci JL., Dixon CB. Evaluation of hand to hand bioelectrical impedance analysis for estimating percentage body fat in young adults. International Journal of Exercise Science. 2009; 2(4): 254- 63. Available from: http://www.intjexersci.com [accessed February 21, 2018].
[24] Pongchaiyakul C., Kosulwat V., Rojroongwasinkul N., Charoenkiatkul S., Thepsuthammarat K., Laopaiboon M., et al Prediction of Percentage Body Fat in Rural Thai Population Using Simple Anthropometric Measurements. Obesity Research Journal. 2005;13 (4):729-38.

[25] Ojo G., Adetola O. The relationship between skin fold thickness and body mass index in estimation body fat percentage on Bowen University students. International Biological and Biomedical Journal. 2017; 3(3): 138-144.

[26] Akindele MO., PhillipsJS.,Igumbor EU. The relationship between Body Fat Percentage and Body Mass Index in Overweight and Obese Individuals in an Urban African Setting. Journal of Public Health in Africa. 2016; 7(1) 15-19. 